\title{
Stabilizing an Unstable Economy: On the Choice of Proper Policy Measures
}

\author{
Toichiro Asada, Chuo University, Tokyo \\ Carl Chiarella, University of Technology, Sydney \\ Peter Flaschel, Bielefeld University \\ Tarik Mouakil, University of Cambridge \\ Christian R. Proaño, Macroeconomic Policy Institute, Düsseldorf \\ Willi Semmler, New School University, New York
}

\begin{abstract}
In the last months, the world's economies were confronted with the largest economic recession since the Great Depression. The occurrence of a worldwide financial market meltdown as a consequence originally stemming from of the crisis in the US subprime housing sector was only prevented by extraordinary monetary and fiscal policy measures implemented at the international level. Although the world economy seems now to be slowing recovering, it is worthwhile exploring the fragility and potentially destabilizing feedbacks of advanced macroeconomies in the context of Keynesian macro models. Fragilities and destabilizing feedback mechanisms are known to be potential features of all markets - the product markets, the labor market, and the financial markets. In this paper we focus in particular on the financial market. We use a Tobin-like macroeconomic portfolio approach, and the interaction of heterogeneous agents on the financial market to characterize the potential instability of the financial markets. Though the study of the latter has been undertaken in many partial models, we focus here on the interconnectedness of all three markets. Furthermore, we also study how labor market, fiscal and monetary policies can stabilize unstable macroeconomies. Besides other stabilizing policies we in particular propose a countercyclical monetary policy that sells assets in the boom and purchases assets in recessions. Modern stability analysis is brought to bear to demonstrate the stabilizing effects of those suggested policies.
\end{abstract}

Special Issue

Managing Financial Instability in Capitalist Economies

JEL E12, E24, E31, E52

Keywords Monetary business cycles; portfolio choice; (in-)stability; stabilizing policy measures

Correspondence Christian R. Proaño, Macroeconomic Policy Institute (IMK), Hans-Böckler-Str. 39, 40476 Düsseldorf, Germany; e-mail: christian.proano@gmail.com

Citation Toichiro Asada, Carl Chiarella, Peter Flaschel, Tarik Mouakil, Christian R. Proaño, and Willi Semmler (2010). Stabilizing an Unstable Economy: On the Choice of Proper Policy Measures. Economics: The OpenAccess, Open-Assessment E-Journal, Vol. 4, 2010-21. doi:10.5018/economics-ejournal.ja.2010-21.

$\mathrm{http}: / / \mathrm{dx}$.doi.org/10.5018/economics-ejournal.ja.2010-21

@ Author(s) 2010. Licensed under a Creative Commons License - Attribution-NonCommercial 2.0 Germany 
conomics: The Open-Access, Open-Assessment E-Journal

\section{Introduction}

As we approach the last decade of the twentieth century, our economic world is in apparent disarray. After two secure decades of tranquil progress following World War II, in the late 1960s the order of the day became turbulence - both domestic and international. Bursts of accelerating inflation, higher chronic and higher cyclical unemployment, bankruptcies, crunching interest rates, and crises in energy, transportation, food supply, welfare, the cities, and banking were mixed with periods of troubled expansions. The economic and social policy synthesis that served us so well after World War II broke down in the mid-1960s. What is needed now is a new approach, a policy synthesis fundamentally different from the mix that results when today's accepted theory is applied to today's economic system.

$$
\text { Minsky (1982, p.3) }
$$

As a result of the financial crisis which started in the relatively small U.S. subprime housing sector, the world experienced in the last year the largest downturn of economic activity since the Great Recession. Since the end of 2007 a hyperactive monetary and fiscal policy implemented in the great majority of countries has aimed at preventing a further financial meltdown, and now the world economy as a whole seems to be on the brink of a stable recovery. It is now time to evaluate our previous understanding of how our economic system works. Further macroeconomic work is thus needed.

As the history of macroeconomic dynamics and business cycles - which recently have been developed as boom-bust cycles - has taught us, fragilities and destabilizing feedbacks are known to be potential features of all markets - the product markets, the labor market, and the financial markets. In this paper we in particular will focus on the financial market. We use a Tobin-like macroeconomic portfolio approach, coupled with the interaction of heterogeneous agents on the financial market, to characterize the potential for financial market instability. Though the study of the latter has been undertaken in many partial models, we focus here on the interconnectness of all three markets. Furthermore, we study 
what potential labor market, fiscal and monetary policies can have in stabilizing intrinsically unstable macroeconomies (it was in particular Minsky (1982) who has put forward many ideas to stabilize an unstable economy). Beside other stabilizing policies we in particular propose a countercyclical monetary policy that sells assets - more specifically, equities of the nonfinancial sector - in the boom and purchases them in recessions. Modern dynamic and stability analysis are brought to bear to demonstrate the stabilizing effects of those suggested policies.

The paper builds on work by Chiarella and Flaschel (2000), Köper (2003) and Chiarella et al. (2005) by using models of that research agenda as the starting point for the proper design of a macrodynamic framework - as well as for the evaluation of labor market, fiscal and monetary policies - which allows in general for large swings in financial and real economic activity. Such a framework revives the macroeconomic portfolio approach that was suggested by Tobin $(1969,1980)$, building on baseline models of the dynamic interaction of the labor market, the product market and financial markets with risky assets. Furthermore, we also build on recent work on the interaction of heterogeneous agents in the financial market. ${ }^{1}$ We allow for heterogeneity in share and goods price expectations and study the financial, nominal and real cumulative feedback chains that may give rise to destabilizing dynamics at the macroeconomic level. The work connects to traditional Keynesian business cycle analysis as Tobin, Minsky, and Akerlof have suggested and thus seems appropriate given that governments world-wide have resorted to Keynesian type policies to combat the current global financial crisis.

The remainder of the paper is organized as follows. Section 1 sketches the main modules of a portfolio approach to Keynesian business cycle theory. The model's steady state properties, as well as the comparative statics of the asset markets are also explored in Section 1 . The potential for fragility and destabilizing feedbacks as well as the proper design of labor market, fiscal and monetary policies are studied in Section 2. Section 2 also proposes a new form of monetary policy that is not only concerned with interest rates, but in particular with countercyclical selling and buying of assets (as recently also proposed by Farmer (2010)) which is,

1 In recent work on behavioral finance the interaction of the fundamentalist and behavioral traders is seen as central in creating bubbles and crashes, see Brunnermeier (2009). 
in spirit, close to the Minsky's (1982) ideas. The stabilizing effects of this policy are also explored. Section 3 concludes.

\section{Asset Markets and Keynesian Business Cycles: A Portfolio Ap- proach}

In the tradition of Tobin $(1969,1980)$, we will depart from the mainstream macroeconomic theory and will provide the structural form of a growth model using a portfolio approach and building on the behavior of heterogeneous agents in the asset markets. In order to discuss details we split the model into appropriate modules that refer to the different sectors of the economy, namely households, firms, and the government (fiscal and monetary authority). Beside presenting a detailed structure of the asset market, we also represent the wage-price-interactions, and connect the financial market to the labor and product market dynamics.

\subsection{Households}

We disaggregate the sector of households into worker households and asset holder households. We begin with the description of the behavior of workers:

\section{Worker households}

$$
\begin{aligned}
\omega & =w / p, \\
C_{w} & =\left(1-\tau_{w}\right) \omega L^{d}, \\
S_{w} & =0, \\
\hat{L} & =n=\text { const. }
\end{aligned}
$$

Eq.(1) gives the definition of the real wage $\omega$ before taxation, where $w$ denotes the nominal wage and $p$ the actual price level. We follow the Keynesian framework by assuming that the labor demand of firms can always be satisfied out of the given labor supply. ${ }^{2}$ Then, according to eq. (2), real income of workers equals the product of real wages times labor demand, which net of taxes $\tau_{w} \omega L^{d}$, equals workers'

\footnotetext{
2 We do not allow for regime switches as they are discussed in Chiarella et al. (2000, ch.5).
} 
consumption, since we do not allow for savings of the workers as postulated in eq. (3). ${ }^{3}$ No savings implies that the wealth of workers is zero at every point in time. This in particular means that the workers do not hold any assets and that they consume instantaneously their disposable income. As is standard in theories of economic growth, we finally assume in eq. (4) a constant growth rate $n$ of the labor force $L$ based on the assumption that labor is supplied inelastically at each moment in time. The parameter $n$ can be easily reinterpreted to be the growth rate of the working population plus the growth rate of labor augmenting technical progress.

The income, consumption and wealth of the asset holders are described by the following set of equations:

Asset holding households

$$
\begin{aligned}
r_{k}^{e} & =\left(Y^{e}-\delta K-\omega L^{d}\right) / K, \\
C_{c} & =\left(1-s_{c}\right)\left[r_{k}^{e} K+i B / p-T_{c}\right], \quad 0<s_{c}<1, \\
S_{p} & =s_{c}\left[r_{k}^{e} K+i B / p-T_{c}\right] \\
& =\left(\dot{M}+\dot{B}+p_{e} \dot{E}\right) / p, \\
W_{c} & =\left(M+B+p_{e} E\right) / p, \quad W_{c}^{n}=p W_{c} .
\end{aligned}
$$

The first equation (5) of this module of the model defines the expected rate of return on real capital $r_{k}^{e}$ to be the ratio of the currently expected real cash flow and the real stock of business fixed capital $K$. The expected cash flow is given by the expected real revenues from sales $Y^{e}$ diminished by real depreciation of capital $\delta K$ and the real wage sum $\omega L^{d}$. We assume that firms pay out all expected cash flow in the form of dividends to the asset holders. These dividend payments are one source of income for asset holders. The second source is given by real interest payments on short term bonds $(i B / p)$ where $i$ is the nominal interest rate and $B$ the stock of such bonds. Summing up these types of interest incomes and taking account of lump sum taxes $T_{c}$ in the case of asset holders (for reasons of simplicity) we obtain the disposable income of asset holder given by the terms in the square brackets of eq. (6), which together with a postulated fixed propensity to consume $\left(1-s_{c}\right)$ out of this income gives us the real consumption of asset holders.

\footnotetext{
3 See Chiarella et al. (2000) for the inclusion of workers' savings into a Keynes-Metzler-Goodwin (KMG) framework.
} 
Real savings of pure asset owners is real disposable income minus their consumption as exposed in eq. (7). The asset owners can allocate the real savings in the form of new money holdings $\dot{M}$, or buy other financial assets, namely short-term bonds $\dot{B}$ or equities $\dot{E}$ at the price $p_{e}$, the only financial instruments that we allow for in the present reformulation of the KMG growth model. Hence, the savings of asset holders must be distributed to these assets as stated in eq. (8). Real wealth of pure asset holders is thus defined in eq. (9) as the sum of the real cash balance, real short term bond holdings and real equity holdings of asset holders. Note that the short term bonds are assumed to be fixed price bonds with a price of one, $p_{b}=1$, and a flexible interest rate $i$.

Along the lines of Tobin's work of portfolio theory, we assume imperfect substitution between three financial assets: $M$ (oney), $B$ (onds) and $E$ (quities). The demand for these three financial assets is given by the following set of equations:

$$
\begin{aligned}
p_{e} E^{d} & =f_{e}\left(r_{e}^{e}, i\right) W_{c}^{n}, \\
B^{d} & =f_{b}\left(r_{e}^{e}, i\right) W_{c}^{n}, \\
M^{d} & =f_{m}\left(r_{e}^{e}, i\right) W_{c}^{n},
\end{aligned}
$$

with

$$
f_{m}(\cdot)+f_{b}(\cdot)+f_{e}(\cdot) \equiv 1
$$

and

$$
r_{e}^{e}=\frac{r_{k}^{e} p K}{p_{e} E}+\pi_{e}^{e}=r_{k}^{e} / q+\pi_{e}^{e}
$$

where the expected rate of return on equities $r_{e}^{e}$ consists as usual of real dividends per unit of equity $\left(r_{k}^{e} p K\right) /\left(p_{e} E\right)=r_{k}^{e} / q$ (by making use of the definition of Tobin's average $q=\frac{p_{e} E}{p K}$ ) and the expected capital gains $\pi_{e}^{e}$, the latter being nothing other than the expected growth rate of equity prices.

The assumed gross substitution property of the analyzed financial assets can be expressed by

$$
\frac{\partial f_{e}(\cdot)}{\partial r_{e}^{e}}>0, \quad \frac{\partial f_{e}(\cdot)}{\partial i}<0
$$




$$
\begin{array}{cl}
\frac{\partial f_{b}(\cdot)}{\partial r_{e}^{e}}<0, & \frac{\partial f_{b}(\cdot)}{\partial i}>0, \\
\frac{\partial f_{m}(\cdot)}{\partial r_{e}^{e}}<0, & \frac{\partial f_{m}(\cdot)}{\partial i}<0,
\end{array}
$$

which means that the demand for all other assets increases whenever the rate of return of the considered asset decreases (for a formal definition see for example Mas-Colell et al. (1995, p. 611)). ${ }^{4}$

While the case of strict inequalities is treated in detail in Köper (2003), in order to characterize in this paper the limits of monetary policy in a more focused way, in the following we assume that ${ }^{5}$

$$
\frac{\partial f_{e}(\cdot)}{\partial i}=0 \quad \text { and } \quad \frac{\partial f_{m}(\cdot)}{\partial r_{e}^{e}}=0,
$$

while all other partial derivatives are strict inequalities. The consequence of the above assumption is that now eqs. $(10-(12)$ postulate a clearly defined portfolio decision making by the asset holders according to which the demand for equities is primarily determined by the expected rate of return on equities $r_{e}^{e}$, the demand for government bonds by $r_{e}^{e}$ as well as by the nominal interest rate $i$, and the money demand solely by $i$. Accordingly, after determining in every moment of time the fraction of their financial wealth to be invested in equities and the fraction to be held in broad money holdings $M_{2}=M+B$, asset holders thus choose their demand for bonds and their transactions demand $M^{d}$ as components of $M_{2}$. This hierarchy in the portfolio decision making is supposed to reflect the situation where asset markets are focused almost exclusively on expected capital gains and where the asset holders may only consider the possibility of significant increases in their money holdings as a second- or third best alternative.

4 Note that the above discussion of asset markets is focused on stocks and not on stock-flow interactions as they are implied by the budget equations of the considered model, where stock-flow consistency is given as shown in Köper (2003) on the basis of the assumed budget equations.

5 We want to stress here however that all propositions and theorems - with the exception of the policy ineffectiveness theorem - also hold in the case of an interest rate elastic equity demand, a situation that in particular will come about if the interest rate departs by too much from its steady state position. 
The consequence of the above assumptions concerning the partial derivatives of the equity and money demand functions is that the subdivision of $M_{2}$ into transactions money and savings deposits takes place primarily on the basis of interest rate changes, so that we thus have an endogenous adjustment of $M$ and $B$, but not of $M_{2}$. Furthermore, due to trading process in the background of this situation, in stock market equilibrium $E=\bar{E}$ again holds, but under a new share price $p_{e}$ and thus also a new money demand $M_{2}$. At the end of this process thus the supply of equities is again held by asset holders and the demand for $M_{2}$ is back at the given stock of it. So for example in times of stress (for the equity market) where people want to go into money hoarding, the equity price will fall significantly without the possibility for the asset holders as a whole to change their actual stock of equities.

Under normal conditions, asset holders thus consider their portfolio choice between $M_{2}$ and $E$ with a strong focus on equities as the central component of their wealth, demanding more (less) equities than they currently hold if the expected rate of return $r_{e}^{e}$ is higher (lower) than its steady state value. This in turn determines the share price $p_{e}$. Equity demand (vs. hoarding) represents therefore the crucial part in the decisions made on the financial markets, while cash management between money $M=M_{1}$ and $B$ is a relatively trivial matter. ${ }^{6}$

In order to complete the modeling of asset holders' behavior, we need to describe the evolution of $\pi_{e}$. In the tradition of recent work on heterogeneous agents in asset markets, see e.g. De Grauwe and Grimaldi (2006), we assume here that there are two types of asset holders who differ with respect to their expectation formation of equity prices. ${ }^{7}$ There are behavioral traders, called chartists, who in principle employ the following adaptive expectations mechanism

$$
\dot{\pi}_{e c}=\beta_{\pi_{e c}}\left(\hat{p}_{e}-\pi_{e c}\right),
$$

${ }^{6}$ Note that even though the stock of the financial assets money $M$, bonds $B$, and equities $E$ is considered as exogenously given in each moment of time, $M, B$ and of course $p_{e}$ are determined through the above portfolio equations, since the central bank has then to adjust to the demands of households with respect to the two assets $M, B$, transforming the initially given values $\bar{M}_{2}=\bar{M}+\bar{B}$ into the components of $\bar{M}_{2}$ that are now desired by the asset holders.

7 Brunnermeier (2009) calls them behavioral and fundamentalist traders. 
where $\beta_{\pi_{e c}}$ is the adjustment speed toward the actual growth rate of equity prices. The other asset holders, the fundamentalists, employ a forward looking expectation formation mechanism

$$
\dot{\pi}_{e f}=\beta_{\pi_{e f}}\left(\eta-\pi_{e f}\right)
$$

where $\eta$ is the fundamentalists' expected long run growth rate of share prices. Assuming that the aggregate expected rate of share price increases $\pi_{e}$ is a weighted average of the two expected growth rates, where the weights are determined according to the sizes of the groups, we obtain

$$
\pi_{e}=\alpha_{\pi_{e c}} \pi_{e c}+\left(1-\alpha_{\pi_{e c}}\right) \pi_{e f}
$$

where $\alpha_{\pi_{e c}} \in(0,1)$ is the ratio of chartists to all asset holders.

Note that the addition of such expectations schemes has an ambiguous effect of the stock market stability properties, with the fairly tranquil fundamentalists' expectations and in contrast the chartists' expectations coming from the behavioral traders, which tend to be destabilizing if they adjust with sufficient strength. Indeed, as suggested e.g. by Brunnermeier (2009), instabilities, bubbles and crashes are overwhelmingly due to the fact that there are heterogeneous agents in the asset market, giving rise to heterogeneous information, heterogeneous beliefs and limits to arbitrage, as also discussed in Abreu and Brunnermeier (2003). ${ }^{8}$

\subsection{Firms}

We consider the behavior of firms by means of two submodules. The first describes the production framework and their investment in business fixed capital and the second introduces the Metzlerian approach of inventory dynamics concerning expected sales, actual sales and the output of firms.

Firms: production and investment

$$
Y^{p}=y^{p} K
$$

8 Note that as a result of this equilibrium specification, the evolution of $\hat{p}_{e}$ cannot be expressed in an explicit manner. Chartist's expectations can however be represented equivalently by means of an integral equation as e.g. Sargent (1987, p.117) expresses adaptive inflationary expectations. 


$$
\begin{aligned}
u & =Y / Y^{p}, \\
L^{d} & =Y / x, \\
e & =L^{d} / L=Y /(x L), \\
q & =p_{e} E /(p K), \\
I & =i_{q}(q-1) K+i_{u}(u-\bar{u}) K+n K, \\
\hat{K} & =I / K \\
p_{e} \dot{E} & =p I+p(\dot{N}-\mathscr{I})
\end{aligned}
$$

Firms are assumed to pay out dividends according to expected profits (expected sales net of depreciation and minus the wage sum), see the above module of the asset owning households. The rate of expected profits $r_{k}^{e}$ is expected real profits per unit of capital as stated in eq. (5). Firms produce output utilizing a production technology that transforms demanded labor $L^{d}$ combined with business fixed capital $K$ into output. For convenience we assume that the production process takes place with a fixed proportion technology. ${ }^{9}$ According to eq. (17) potential output $Y^{p}$ is given at each moment of time by a fixed coefficient $y^{p}$ times the existing stock of physical capital. Accordingly, the utilization of productive capacities is given by $u$, the ratio of actual production $Y$ and the potential output $Y^{p}$. The fixed proportions in production give rise to a constant output-labor coefficient $x$, by means of which we can deduce labor demand from goods market determined output as in eq. (19). The ratio $L^{d} / L$ thus defines the rate of employment in the model.

The economic behavior of firms must include their investment decision with regard to business fixed capital, which is determined independently of the savings decision of households. We here model investment decisions per unit of capital as a function of the deviation of Tobin's $q$ (see Tobin (1969)) from its long run value 1 , and the deviation of actual capacity utilization from a normal rate of capital utilization. We employ here Tobin's average $q$ which is defined in eq. (21) as the ratio of the nominal value of equities and the reproduction costs for the existing stock of capital. Investment in business fixed capital is thus reinforced when $q$ exceeds one, and is reduced when $q$ is smaller then one. This influence is

\footnotetext{
9 See Chiarella et al. (2000, ch.4) for the treatment of a production function with smooth factor substitution and a discussion as to why this assumption is not as restrictive as might be believed by many economists.
} 
represented by the term $i_{q}(q-1)$ in equation (22). The term $i_{u}(u-\bar{u})$ models the component of investment which is due to the deviation of utilization rate of physical capital from its non accelerating inflation value $\bar{u}$. The last component $n K$ ( $n$ being the exogenously given natural growth rate) takes account of the natural growth rate $n$ which is necessary for steady state analysis if natural growth is considered as exogenously given. Eq. (24) is the budget constraint of the firms. Investment in business fixed capital and unintended changes in the inventory stock $p(\dot{N}-\mathscr{I})$ must be financed by issuing equities, since equities are the only financial instrument of firms in this paper. Capital stock growth finally is given by net investment per unit of capital $I / K$ in this demand-determined model of the short-run equilibrium position of the economy.

Next we discuss the inventory dynamics following Metzler (1941) and Franke (1996).

Firms output adjustment:

$$
\begin{aligned}
N^{d} & =\alpha_{n^{d}} Y^{e}, \\
\mathscr{I} & =n N^{d}+\beta_{n}\left(N^{d}-N\right), \\
Y & =Y^{e}+\mathscr{I}, \\
Y^{d} & =C+I+\delta K+G, \\
\dot{Y}^{e} & =n Y^{e}+\beta_{y^{e}}\left(Y^{d}-Y^{e}\right), \\
\dot{N} & =Y-Y^{d}, \\
S_{f} & =Y-Y^{e}=\mathscr{I},
\end{aligned}
$$

where $\alpha_{n^{d}}, \beta_{n}, \beta_{y^{e}} \geq 0$.

Eq. (25) states that the desired stock of physical inventories, denoted by $N^{d}$, is assumed to be a fixed proportion of the expected sales. The planned investments in inventories $\mathscr{I}$ follow a sluggish adjustment process toward the desired stock $N^{d}$ according to eq. (26). Taking account of this additional demand for goods, eq. (27) writes the production $Y$ as equal to the expected sales of firms plus $\mathscr{I}$.

To explain the expectation formation for goods demand, we need the actual total demand for goods which in (28) is given by consumption (of private households and the government) and gross investment by firms. From the observation of current actual demand $Y^{d}$, which is assumed to be always satisfied, the dynamics 
of expected sales is given in eq. (29), which models expectations as the outcome of an error correction process that incorporates also the natural growth rate $n$ in order take account of the fact that this process operates in a growing economy. The adjustment of sales expectations is driven by the prediction error $\left(Y^{d}-Y^{e}\right)$, with an adjustment speed that is given by $\beta_{y^{e}}$. Actual changes in the stock of inventories are described in eq. (30) by the deviation of production from goods demanded.

The savings of the firms $S_{f}$ is as usual defined by income minus consumption. Because firms are assumed to not consume anything, their income equals their savings and is given by the excess of production over expected sales, $Y-Y^{e}$. According to the production account in Table 1 the gross accounting profit of firms finally is $r_{k}^{e} p K+p \mathscr{I}=p C+p I+p \delta K+p \dot{N}+p G$. Substituting in the definition of $r_{k}^{e}$ from eq. (5), we compute that $p Y^{e}+p \mathscr{I}=p Y^{d}+p \dot{N}$ or equivalently $\left(Y-Y^{e}\right)=\mathscr{I}$ as stated in eq. (31).

\subsection{Fiscal and Monetary Authorities}

The role of the government in this paper is to provide the economy with public (non-productive) services within the limits of its budget constraint.

$$
\begin{aligned}
T & =\tau_{w} \omega L^{d}+T_{c}, \\
T_{c}-i B / p & =t_{c} K, \quad t_{c}=\text { const. } \\
G & =g K, \quad g=\text { const. } \\
S_{g} & =T-i B / p-G, \\
\hat{M} & =\mu, \\
\dot{B} & =p G+i B-p T-\dot{M} .
\end{aligned}
$$

Public purchases (and interest payments) are financed through taxes, through newly printed money, or newly issued fixed-price bonds $\left(p_{b}=1\right)$. Note that the budget constraint gives rise to some repercussion effects between the public and the private sector. ${ }^{10}$ We model the tax income consisting of taxes on wage income and lump sum taxes on capital income $T_{c}$. With regard to the real purchases of the government for the provision of government services we assume, again as in Sargent (1987),

\footnotetext{
${ }^{10}$ See for example Sargent (1987, p.18) for the introduction of net of interest taxation rules.
} 
conomics: The Open-Access, Open-Assessment E-Journal

Table 1: The four Activity Accounts of the Firms

\begin{tabular}{ll}
\hline Uses & Resources \\
\hline \hline & Production Account of Firms: \\
Depreciation $p \delta K$ & Private consumption $p C$ \\
Wages $w L^{d}$ & Gross investment $p I+p \delta K$ \\
Gross accounting profits $\Pi=r_{k}^{e} p K+p \mathscr{I}$ & Inventory investment $p \dot{N}$ \\
& Public consumption $p G$ \\
\hline & Income Account of Firms: \\
Dividends $r_{k}^{e} p_{y} K$ & Gross accounting profits $\Pi$ \\
Savings $p \mathscr{I}$ & \\
\hline
\end{tabular}

Accumulation Account of Firms:

Gross investment $p I+p \delta K$ Inventory investment $p \dot{N}$
Depreciation $p \delta K$

Savings $p \mathscr{I}$

Financial deficit $F D$

Financial Account of Firms:

Equity financing $p_{e} \dot{E}$

that these are a fixed proportion $g$ of real capital, which taken together allows us to represent fiscal policy by means of simple parameters in the intensive form representation of the model and in the steady state considerations to be discussed later on. The real savings of the government, which is a deficit if it has a negative sign, is defined in eq. (35) by real taxes minus real interest payments minus real public services.

Concerning monetary policy, it should be clear that under a totally inelastic equity demand function with respect to the interest rate (as assumed above), a monetary policy only based on the management of the short-term rate of interest is ineffective in terms of macroeconomic stabilization, unless it is capable of impacting capital gains expectations on the stock market. This holds for money supply steering as well as for the now fashionable interest rate policy rules of 
Taylor type, since such policies would only affect the cash management process within the given stock of liquid assets, as previously assumed. This result is a limit case of what Keynes already observed in the General Theory, where he wrote:

Where, however, (as in the United States, 1933-1934) open-market operations have been limited to the purchase of very short-dated securities, the effect may, of course, be mainly confined to the very short-term rate of interest and have but little reaction on the much more important long-term rates of interest.

Keynes (1936, p.197)

For reasons of expositional simplicity we thus assume for now that money supply grows at a given rate $\mu=$ const. (we will relax this assumption below). Eq. (36) thus shows that money is assumed to enter the economy via open market operations of the central bank, which buys short-term bonds from the asset holders when issuing new money. Then the changes in the short-term bonds supplied by the government are given residually in eq. (37), which is the budget constraint of the governmental sector.

\subsection{Wage-Price Interactions}

We now turn to a module of our model that can be the source of significant centrifugal forces within the complete model. These are the three laws of motion of the wage-price spiral. Picking up the approach of Rose (1967) ${ }^{11}$ of two short-run Phillips curves, i) the wage Phillips curve and ii) the price Phillips curve, the relevant dynamic equations can be written as

$$
\begin{aligned}
\hat{w} & =\beta_{w}(e-\bar{e})+\kappa_{w} \hat{p}+\left(1-\kappa_{w}\right) \pi^{c}, \\
\hat{p} & =\beta_{p}(u-\bar{u})+\kappa_{p} \hat{w}+\left(1-\kappa_{p}\right) \pi^{c}, \\
\dot{\pi}^{c} & =\beta_{\pi^{c}}\left(\alpha \hat{p}+(1-\alpha)(\mu-n)-\pi^{c}\right) .
\end{aligned}
$$

where $\beta_{w}, \beta_{p}, \beta_{\pi^{c}} \geq 0,0 \leq \alpha \leq 1$, and $0 \leq \kappa_{w}, \kappa_{p} \leq 1$. This approach makes use of the assumption that relative changes in money wages are influenced by demand

${ }^{11}$ See also Rose (1990). 
pressure in the market for labor and price inflation (cost-pressure) terms. Price inflation in turn depends on demand pressure in the market for goods and on money wage (cost-pressure) terms. Wage inflation therefore is described in eq. (38) on the one hand by means of a demand pull term $\beta_{w}(e-\bar{e})$, which states that relative changes in wages depends positively on the gap between actual employment $e$ and its NAIRU value $\bar{e}$. On the other hand, the cost push elements in wage inflation is the weighted average of short-run (perfectly anticipated) price inflation $\hat{p}$ and medium run expected overall inflation $\pi^{c}$, where the weights are given by $\kappa_{w}$ and $1-\kappa_{w}$. The price Phillips curve is quite similar, it also displays a demand pull and a cost push component. The demand pull term is given by the gap between capital utilization and its NAIRU value, $(u-\bar{u})$, and the cost push element is the $\kappa_{p}$ and $1-\kappa_{p}$ weighted average of short run wage inflation $\hat{w}$ and expected medium run overall inflation $\pi^{c}$.

What is left to model is the expected medium run inflation rate $\pi^{c}$. We postulate in eq. (40) that changes in expected medium run inflation are due to an adjustment process towards a weighted average of the current inflation rate and steady state inflation. Thus we introduce here a simple kind of forward looking expectations into the economy. This adjustment is driven by an adjustment velocity $\beta_{\pi^{c}}$.

\subsection{Asset Markets Equilibrium}

Based on the Tobin (1969) portfolio approach to the behavior of asset holders (see also Franke and Semmler (1999)), we postulate that the following equilibrium conditions for the asset markets

$$
\begin{aligned}
p_{e} E & =p_{e} E^{d}=f_{e}\left(r_{e}^{e}\right) W_{c}^{n}, \quad r_{e}^{e}=r_{k}^{e} / q+\pi_{e}^{e}, \\
B & =B^{d}=f_{b}\left(r_{e}^{e}, i\right) W_{c}^{n} . \\
M & =M^{d}=f_{m}(i) W_{c}^{n}
\end{aligned}
$$

always hold and thus determine the nominal rate of interest $i$ and the price of equities $p_{e}$ as statically endogenous variables in the model, as the trade between the asset holders induces a process that makes asset prices fall or rise in order to equilibrate demands and supplies.

In the short run (in continuous time) the structure of wealth of asset holders $W_{c}^{n}$ is, disregarding changes in the share price $p_{e}$, given to them and for the model. 
Since the functions $f_{m}(\cdot), f_{b}(\cdot)$, and $f_{e}(\cdot)$, introduced in eqs. (10) to (12) satisfy the well known conditions

$$
\begin{aligned}
f_{m}(\cdot)+f_{b}(\cdot)+f_{e}(\cdot) & \equiv 1, \\
\frac{\partial f_{m}(\cdot)}{\partial z}+\frac{\partial f_{b}(\cdot)}{\partial z}+\frac{\partial f_{e}(\cdot)}{\partial z} & \equiv 0, \quad \forall z \in\left\{i, r_{e}^{e}\right\} .
\end{aligned}
$$

These conditions guarantee that the number of independent equations is equal to the number of statically endogenous variables $\left(i, p_{e}\right)$ that the asset markets are assumed to determine at each moment in time. Note also that all asset supplies here are given magnitudes at each moment in time and recall from eq. (13) that $r_{e}^{e}$ is given by $r_{k}^{e} / q+\pi_{e}$ and thus varies at each point in time solely due to variations in the share price $p_{e} .^{12}$

\subsection{The Model in Intensive Form}

The model's intensive form (see the appendix for the derivation of the following equations) is given by

$$
\begin{aligned}
\hat{\omega}= & \kappa\left[\left(1-\kappa_{p}\right) \beta_{w}(e-\bar{e})+\left(\kappa_{w}-1\right) \beta_{p}(u-\bar{u})\right], \\
\dot{\pi}^{c}= & \alpha \beta_{\pi^{c}} \kappa\left[\beta_{p}(u-\bar{u})+\kappa_{p} \beta_{w}(e-\bar{e})\right]+(1-\alpha) \beta_{\pi^{c}}\left(\mu-n-\pi^{c}\right), \\
\hat{l}= & n-i(\cdot)=-i_{q}(q-1)-i_{u}(u-\bar{u}), \\
\dot{y}^{e}= & \beta_{y^{e}}\left(y^{d}-y^{e}\right)+(n-i(\cdot)) y^{e} \\
\dot{v}= & y-y^{d}-i(\cdot) v \\
\dot{\pi}_{e}= & \alpha_{\pi_{e c}} \beta_{\pi_{e c}}\left(\hat{p}_{e}-\pi_{e c}\right)+\left(1-\alpha_{\pi_{e c}}\right) \beta_{\pi_{e f}}\left(\eta-\pi_{e f}\right), \\
\dot{b}= & g-t_{c}-\tau_{w} \omega l^{d}-\mu m \\
& -b\left(\kappa\left[\beta_{p}(u-\bar{u})+\kappa_{p} \beta_{w}(e-\bar{e})\right]+\pi^{c}+i(\cdot)\right), \\
\dot{m}= & m \mu-m\left(\kappa\left[\beta_{p}(u-\bar{u})+\kappa_{p} \beta_{w}(e-\bar{e})\right]+\pi^{c}+i(\cdot)\right) .
\end{aligned}
$$

As shown above, the dynamics in extensive form can therefore be reduced to eight differential equations, where however the law of motion for share prices

\footnotetext{
${ }^{12}$ It should be again pointed out that the above portfolio structure implies that the central bank's monetary policy can only affect the asset markets significantly through its effects on the rate of profit of firms $r$ or the expectations of capital gains $\pi_{e}^{e}(\bar{E}, p, K$ being given magnitudes), since we have assumed that $\partial f_{e}(\cdot) / \partial i=0$.
} 
has not yet been determined, or to seven differential and one integral equation which is easier to handle than the alternative representation, since there is then no law of motion for the development of future share prices to be calculated. Note with respect to these dynamics that economic policy (fiscal and monetary) is still represented in very simple terms here, since money supply is growing at a given rate and since government expenditures and taxes on capital income net of interest payments per unit of capital are given parameters. This makes the dynamics of the government budget constraint (see eq. (52), the law of motion for bonds per unit of capital $b$ ) a very trivial one as in Sargent (1987, ch.5), and thus leaves the problems associated with these dynamics a matter for future research. The advantage is that fiscal policy can be discussed in a very simple way here by means of just three parameters.

A comparison of the present dynamics with those of the previous models of the authors ${ }^{13}$ reveals that there are now two variables from the financial sector that feed back to the real dynamics in this extended system, the bond to capital ratio $b$ representing the evolution of government debt and Tobin's average $q$. The first (dynamic) variable however only influences the real dynamics since it is one of the factors that influences the statically endogenous variable $q$ which in turn enters the investment function as a measure of the firms' performance. Government bonds do not influence the economy in other ways, since there are not yet wealth effects in consumption and since the interest income channel to consumption has been suppressed by the particular assumption about tax collection concerning capital income.

It should be pointed out that in the present theoretical framework the influence of the (real) interest rate in the investment function is now absent, and that Tobin's $q$ provides instead the channel by which investment behavior is reacting to the results brought about by the financial markets. We do this mainly due to expositional clarity as our focus primarily lies on the interaction between stock and real markets, on the one hand, and also because its inclusion would not significantly change the stability properties of the model as long as equity prices are primarily focused on capital gains expectations and thus not directly affected by changes in the nominal interest rate. The case of a direct impact of the nominal and real rate of interest in

${ }^{13}$ See Chiarella and Flaschel (2000) and Chiarella et al. (2000). 
the investment function against the background of a Taylor-like monetary policy rule is treated in detail in Chiarella et al. (2005).

A feature of the present dynamics is that there are no laws of motion left implicit. The model contains now a completely formulated dynamics, but still one where the real financial interaction is represented in very basic terms. Price inflation (via real balances and real bonds) and the expected rate of return on capital (via the rate of return on dividends) influence the behavior of asset markets via their laws of motion such as gross substitution of assets and expectation dynamics for asset prices, while the reaction of asset markets feeds back into the real part of the economy instantaneously through the change in Tobin's $q$ that they (and the dynamics of expected capital gains) bring about.

Before we come to a consideration of the model's steady state and its stability properties, as well as among other things the potentially destabilizing role of chartist-type capital gains expectations, we discuss the full structure of our model by means of what is shown in Figure 1. This figure highlights the destabilizing role of the wage-price spiral, where now - due to the assumed investment behavior we always have a positive impact of real wages on aggregate demand and thus the result that wage flexibility will be destabilizing (if not counteracted by its effects on expected profits and their effect on financial markets and Tobin's $q$ ). We have already indicated that financial markets adjust towards their equilibrium in a stable manner as long as we disregard the expectations dynamics on the financial market. Monetary policy, whether money supply oriented and thus of type $M(i, p)$, or of a Taylor type $i(M, \hat{p})$ should - via the gross substitution effects - also contribute to the stability of the financial markets, and fiscal policy impacts the goods and the financial markets either in orthodox manner or as of a Keynesian countercyclical kind. Note however that due to the very intertwined dynamical structure of the model it is not clear how fiscal policy in detail might contribute to the shaping of the business cycle. Finally, there remains the discussion of the self-reference within the asset markets (that is the closed loop structure between capital gains expectations and actual capital gains) which must also be the most difficult part of the considered dynamical system, the details of which must be left to future research. 
A Keynesian Portfolio Approach to Ec. Growth (no Keynes- or Mundell-Effect Channels yet)

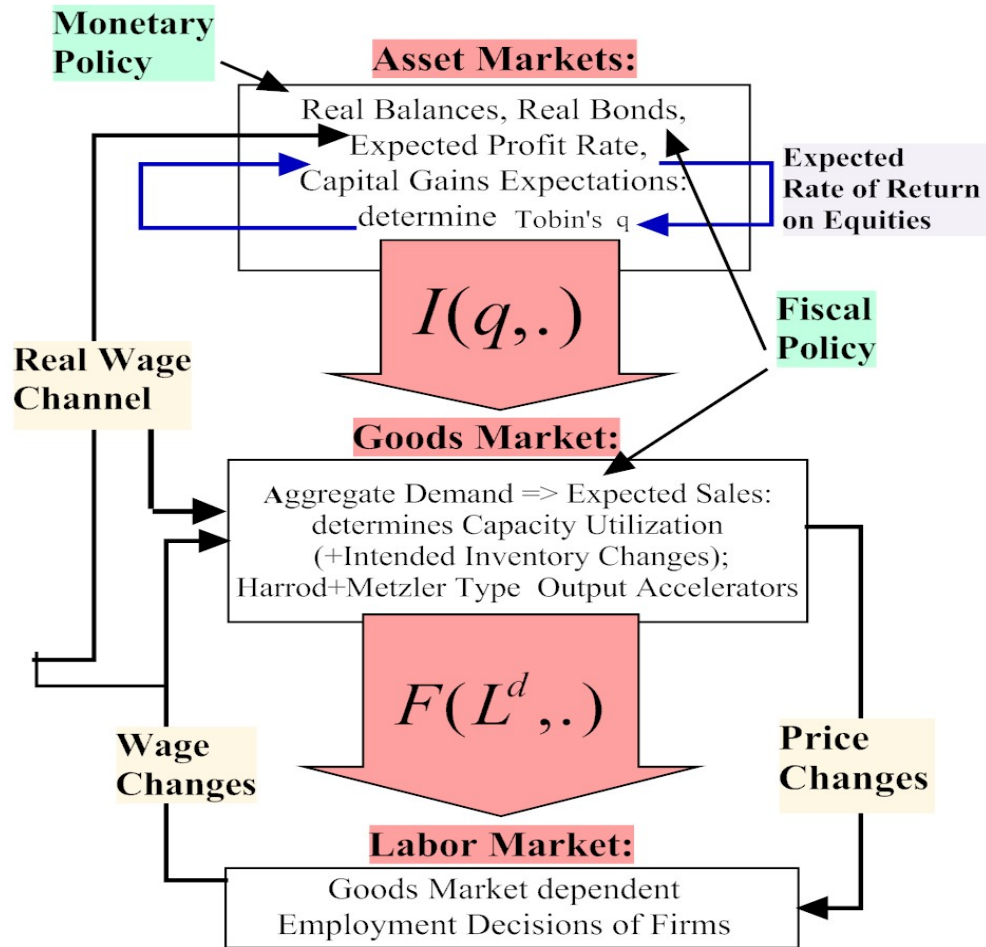

Demand pressure / cost pressure determined wage-price spiral

Figure 1: Keynes' causal downward nexus (from self-contained financial markets dynamics to economic activity), repercussive feedback chains (from economic activity to expected returns on equities), supply side dynamics (the wage-price spiral) and policy rules in a Keynesian model with portfolio dynamics 


\subsection{Steady State Considerations}

In this section we show the existence of a steady state in the economy under consideration. We here stress that this can be done independently of the analysis given in the following section on the comparative statics of the asset market equilibrium system, since Tobin's $q$ is given by 1 in the steady state via the real part of the model and since the portfolio equations can be uniquely solved in conjunction with the government budget constraint for the three variables $i, m, b$ which they then determine. ${ }^{14}$

As the model is formulated we have the following nine state variables

$$
m, b, y^{e}, \omega, l, v, \pi^{c}, \pi_{e f}, \pi_{e c}
$$

in the considered dynamical system. We have written these state variables in the order they will used in the stability analysis in a following section. This order is generally not the same as in the steady state analysis of the model where causalities of a different type (than in stability analysis) are involved.

Lemma 1 Assume $s_{c}>\tau_{w}$ and $s_{c} r^{e 0}>n+g-t_{c}$. Assume furthermore that the ratio

$$
\bar{\phi}=\frac{g-t_{c}-\tau_{w} \omega l^{d o}}{g-t_{c}-\tau_{w} \omega l^{d o}+\mu}
$$

- to be explicitly derived below - has a positive numerator, meaning that the government runs a primary deficit in the steady state. The dynamical system given by equations (46) to (53) possesses a unique interior steady state solution $\left(\omega^{o}, l^{o}, m^{o}>0\right)$ with equilibrium on the asset markets, if the fundamentalists long run reference of the increase in equity prices equals the steady state inflation rate of goods prices

$$
\eta=\hat{p}^{o}, \quad \text { and }
$$

\footnotetext{
${ }^{14}$ Note that while $m$ and $b$ are of course varying over time, for the determination of $q$ and $i$ (the variables that bring the asset markets into equilibrium) $m$ and $b$ are given magnitudes at each point in time.
} 


$$
\begin{array}{r}
\lim _{i \rightarrow 0}\left(f_{m}\left(i, r^{e 0}+\pi_{e}^{o}\right)+f_{b}\left(i, r^{e 0}+\pi_{e}^{o}\right)\right)<\bar{\phi}, \text { and } \\
\lim _{i \rightarrow \infty}\left(f_{m}\left(i, r^{e 0}+\pi_{e}^{o}\right)+f_{b}\left(i, r^{e 0}+\pi_{e}^{o}\right)\right)>\bar{\phi}
\end{array}
$$

holds true. ${ }^{15}$

Proof: If the economy rests in a steady state, then all intensive variables stay constant and all time derivatives of the system become zero. Thus by setting the left hand side of the system of eqs. (46) to (53) equal to zero, we can deduce the steady state values of the variables.

From eq. (48) we can derive that $i(\cdot)^{o}=n$ holds, from eq. (49) we get $y^{e o}=y^{d o}$, and from eq. (53) that $\mu=\left(\kappa\left[\beta_{p}(u-\bar{u})+\kappa_{p} \beta_{w}(e-\bar{e})\right]+\pi^{c}+i(\cdot)\right)$. Substituting the last relation into eq. (40) and using $i(\cdot)^{o}=n$ we obtain with $\alpha \beta_{\pi} \neq-(1-\alpha) \beta_{\pi}^{c}$ that $\mu-n-\pi^{c}=0$ and $\kappa\left[\beta_{p}(u-\bar{u})+\kappa_{p} \beta_{w}(e-\bar{e})\right]=0$. Thus we have for $u-\bar{u}$ and $e-\bar{e}$ the two equations

$$
\begin{aligned}
& u-\bar{u}=-\kappa_{p} \beta_{w}(e-\bar{e}) / \beta_{p}, \\
& u-\bar{u}=\left(1-\kappa_{p}\right) \beta_{w}(e-\bar{e}) /\left[\left(1-\kappa_{w}\right) \beta_{p}\right] .
\end{aligned}
$$

By assumption we have $\beta_{p}, \beta_{w}>0$ and $0 \leq \kappa_{p}, \kappa_{w} \leq 1$, so $e-\bar{e}$ must equal zero in order that the last two equations be fulfilled. When $e=\bar{e}$, then according to eq. (46) we know that $u=\bar{u}$. Then eq. (48) leads to $q^{o}=1$.

With these relations one can easily compute the unique steady state values of the variables $y^{e}, l, \pi^{c}, v, \omega$ as

$$
\begin{aligned}
y^{e o} & =\frac{y^{o}}{1+n \alpha_{n^{d}}}, \quad \text { with } y^{o}=\bar{u} y^{p}, \\
l^{o} & =y^{o} /(\bar{e} x), \\
\pi^{c o} & =\mu-n, \\
v^{o} & =\alpha_{n^{d}} y^{e o}, \\
\omega^{o} & =\frac{y^{e o}-n-\delta-g-\left(1-s_{c}\right)\left(y^{e o}-\delta-t_{c}\right)}{\left(s_{c}-\tau_{w}\right) l^{d o}}, \\
r^{e 0} & =y^{e o}-\delta-\omega^{o} l^{d o} .
\end{aligned}
$$

\footnotetext{
${ }^{15}$ Note with respect to this part of the lemma that the steady state values used in the above assumption are calculated before this assumption is applied to a determination of the steady state value of the nominal rate of interest.
} 
All these values are determined on the goods and labor markets. The steady state value of the real wage has in particular been derived from the goods market equilibrium condition that must hold in the steady state and it is positive under the assumptions made in lemma 1.

We next take account of the asset markets, which determine the values of the short-term interest rate $i$ (which is now bears the burden of clearing the asset markets), but now in conjunction with the determination of the steady state for $m$ and $b$, where $m+b$ is determined through the government budget constraint. This is the case because the steady state rate of return on equities relies, on the one hand, solely on $r^{e 0}$ (since $q$ has been determined through the condition $i(\cdot)=n$ and shown to equal one in steady state) and, on the other hand, on the expected inflation rate of share prices

$$
r_{e}^{e 0}=r^{e 0}+\pi_{e}^{o}
$$

which equals the goods price inflation rate in the steady state as will be shown below.

The steady state values of the two kinds of expectations about the inflation rate of equity prices (of chartists and fundamentalists) are

$$
\pi_{e f}^{o}=\eta, \quad \pi_{e c}^{o}=\eta
$$

from which one can derive that $\pi_{e}^{o}=\eta=\hat{p}^{o}=\pi^{c o}=\mu-n$ must hold. We have seen that, in the steady state, Tobin's $q$ equals one and its time derivative equals zero, so that we can derive

$$
\begin{aligned}
\dot{q} & =\frac{\left(\dot{p}_{e} E+p_{e} \dot{E}\right) p K-p_{e} E(\dot{p} K+p \dot{K})}{p^{2} K^{2}}=0 \\
& \Rightarrow \frac{\dot{p}_{e} E+p_{e} \dot{E}}{p K}=\hat{p}+n .
\end{aligned}
$$

According to eq. (24) we have $p_{e} \dot{E}=p I+p(\dot{N}-\mathscr{I})$ we thus get in the steady state that $p_{e} \dot{E}=p I$. Inserting this into the last implication shown we get $\hat{p}_{e}=\hat{p}$ and thus as an important finding that $\eta=\mu-n$ must hold in order to allow for a steady state.

Let us now determine the steady state values of the stocks of real cash balances and the stock of bonds. These values have to be solved for in conjunction with the 
steady state interest rate $i^{o}$ which is now solely responsible for clearing the asset markets, because the result that Tobin's $q=1$ has already been determined on the real markets.

The budget constraint of the government is given in intensive form by

$$
\dot{b}+\dot{m}=g-t_{c}-\tau_{w} \omega l^{d}-(b+m)(\hat{p}+i(\cdot)) .
$$

One therefore obtains in the steady state that

$$
b^{o}+m^{o}=\left(g-t_{c}-\tau_{w} \omega l^{d}\right) / \mu .
$$

Furthermore, consider the asset demand functions given by eqs. (12) and (11), namely

$$
\begin{aligned}
m & =f_{m}(\cdot)(m+b+q), \quad q=1, \\
b & =f_{b}(\cdot)(m+b+q), \quad q=1 .
\end{aligned}
$$

The left side of the last two equations are the supplied amounts and the right sides represent the demand for the assets $m, b$.

Using now eq. (62) in the form

$$
\mu\left(m^{o}+b^{o}\right)=g-t_{c}-\tau_{w} \omega l^{d},
$$

the system of three linear independent eqs. (63) to (65) can be used to deduce the three unique steady state values $i^{o}, b^{o}$, and $m^{o}$ which we will show below.

Beginning with the steady state interest rate we sum eqs. (63) and (64) and multiply by $\mu$, obtaining

$$
\mu\left(m^{o}+b^{o}\right)=\left(f_{m}^{o}+f_{b}^{o}\right) \mu\left(m^{o}+b^{o}+1\right),
$$

where $f_{m}^{o}$ and $f_{b}^{o}$ denote the values of $f_{m}\left(i^{o}, r^{e 0}+\pi_{e}^{o}\right)$ and $f_{b}\left(i^{o}, r^{e 0}+\pi_{e}^{o}\right)$ respectively. Substituting in the budget constraint in the form of eq. (65) we get

$$
f_{m}^{o}+f_{b}^{o}=\bar{\phi}
$$

with $\bar{\phi}=\frac{g-t_{c}-\tau_{w} \omega^{o} l^{d o}}{g-t_{c}-\tau_{w} \omega^{o} l^{d o}+\mu}$. From property (45) and (14) we can conclude that

$$
\frac{\partial\left(f_{m}+f_{b}\right)}{\partial i}>0
$$


which implies that the cumulated demand for money and bonds is a strictly increasing function in the variable $i$.

If $\lim _{i \rightarrow 0}\left(f_{m}\left(i, r^{e o}+\pi_{e}^{o}\right)+f_{b}\left(i, r^{e o}+\pi_{e}^{o}\right)\right)<\bar{\phi}$ and $\lim _{i \rightarrow \infty}\left(f_{m}\left(i, r^{e o}+\pi_{e}^{o}\right)+\right.$ $\left.f_{b}\left(i, r^{e o}+\pi_{e}^{o}\right)\right)>\bar{\phi}$ then by monotonicity and continuity there must be a value of $i$, which equilibrates the asset markets in the above aggregated form. Then, steady state supplies of $m$ and $b$ can be calculated by eqs. (63) and (64) in a unique way, based on the steady state interest rates $i=i^{o}$ and $r_{e}^{e 0}=r^{e 0}+\pi_{e}$. This concludes the derivation of the uniquely determined steady state values for our dynamical system (46) to (53) which in turn when inserted into this system indeed imply that the dynamics is at a point of rest in this situation.

Note that inflation rates are uniform throughout in this model type (also for stock prices) and that government $\operatorname{debt} B$ is growing with the same rate as money supply $\mu$ in the steady state, while the real sector is growing with the natural rate $n$ (which is also the growth rate of equity supply). We observe finally that the calculation of the steady state value of the rate of wage and the rate of return on capital can be simplified when it is assumed that government expenditures are given by $g+\tau_{w} \omega l^{d}$ in place of only $g$.

\section{Dampening Unstable Business Cycles}

As we have shown in previous related work, see e.g. Chiarella and Flaschel (2000) and Chiarella et al. (2000), the considered model type discussed above is capable of producing various dynamic outcomes and is thus a very open one with respect to possible business cycle implications. In particular, it features a variety of macroeconomic channels which may be of an intrinsically destabilizing nature, even though - through their interaction with other (stabilizing) mechanisms - they may not necessarily lead to a full-fledged macroeconomic instability. There are for example two accelerator effects involved in the dynamics, the Metzlerian inventory accelerator mechanism and the Harrodian fixed business investment accelerator. We therefore expect that increasing the parameters $\beta_{n}$ and $i_{u}$ will also be destabilizing and also lead to Hopf bifurcations and other complex dynamic behavior. Either wage or price flexibility will, through their effects on the expected rate of return 
on capital, and from there on asset markets, be destabilizing and lead to Hopfbifurcations, limit cycles or (locally) purely explosive behavior eventually. ${ }^{16}$

Given the potentially destabilizing influence of these and other macroeconomic channels, the proper choice and design of active labor, fiscal and monetary policy is central for the achievement of a stable macroeconomic environment. In the following we discuss various policy options meant to assure such a macroeconomic stability.

\subsection{Labor Market and Fiscal Policies}

Next we want to raise the question of what might stabilize our macroeconomic dynamics. Let us first suppose that all assumptions stated in lemma 1 hold. What is left to analyze then is the dynamical behavior of the system, when it is displaced from its steady state position, but still remains in a neighborhood of the steady state. In the following we provide propositions, which in sum imply that there must be a locally stable steady state, if some sufficient conditions that are very plausible from a Keynesian perspective are met.

We begin with an appropriate subsystem of the full dynamics for which the Routh-Hurwitz conditions can be shown to hold. Setting $\beta_{p}=\beta_{w}=\beta_{\pi_{e f}}=\beta_{\pi_{e c}}=$ $\beta_{n}=\beta_{\pi^{c}}=0, \beta_{y^{e}}>0$, and keeping $\pi^{c}, \pi_{e}, \omega, \nu$ thereby at their steady state values we get the following subdynamics of state variables $m, b$ and $y^{e}$ which are then independent of the rest of the system: ${ }^{17}$

$$
\begin{aligned}
\dot{m} & =m\left(\mu-\left[\pi_{o}^{c}+i(\cdot)\right]\right), \\
\dot{b} & =g-t_{c}-\tau_{w} \omega \frac{y}{x}-\mu m-b\left(\pi_{o}^{c}+i(\cdot)\right), \\
\dot{y}^{e} & =\beta_{y^{e}}\left[c+i(\cdot)+\delta+g-y^{e}\right]+y^{e}(n-i(\cdot)) .
\end{aligned}
$$

\footnotetext{
${ }^{16}$ The Mundell or real rate of interest effect is not so obviously present in the considered dynamics as there is no long real rate of interest involved in the investment (or consumption) behavior. Increasing expected price inflation does not directly increase aggregate demand, economic activity and thus the actual rate of price inflation. This surely implies that the model needs to be extended in order to take account of the role that is generally played by the real rate of interest in macrodynamic models.

${ }^{17}$ Note that $l$ may vary, but does not feed back into the presently considered subdynamics.
} 
Proposition 1 The steady state of the system of differential equations (67) is locally asymptotically stable if $\beta_{y}$ is sufficiently large, the investment adjustment speed $i_{u}$ concerning deviations of capital utilization from the normal capital utilization is sufficiently small and the partial derivatives of desired cash balances with respect to the interest rate $\partial f_{m} / \partial i$ and the rate of return on equities $\partial f_{m} / \partial r_{e}^{e}$ are sufficiently small. Moreover the equity market must be in a sufficiently tranquil state, i.e., the partial derivative $\partial f_{e} / \partial r_{e}^{e}$ must also be sufficiently small.

Proof: See Köper (2003), also with respect to all other following propositions of this section.

The proposition asserts that local asymptotic stability at the steady state of the considered subdynamics holds when the demand for cash is not very much influenced by the rates of return on the financial asset markets, ${ }^{18}$ the accelerating effect of capacity utilization on the investment behavior is sufficiently small, and the adjustment speed of expected sales towards actual demand is fast enough. Moreover, and this is an important condition, the stock markets must be sufficiently tranquil in the reaction to changes in the rate of return on equities, i.e., they are in particular not close to a liquidity trap.

In order to show how policy can enforce the validity of this situation we need some preliminary observations first. In the given structure of financial markets it is natural to assume that even $\partial f_{m} / \partial r_{e}^{e}=0$ and $\partial f_{e} / \partial i=0$ holds true, since fixprice bonds are equivalent to saving deposits and thus form together with money $M$ just what is named $M_{2}$ in the literature. The internal structure of $M_{2}$ is however just a matter of proper cash management and should therefore imply that the rate of return $r_{e}^{e}$ on equities does not matter for it. The latter only concerns the demand for equities versus the demand for the aggregate $M_{2}$ which both solely then depend on the rate of return for equities, since the dependence on the rate of interest cancel when $M_{2}$ is formed.

Moreover, since the transaction costs for reallocations within $M_{2}$ can be assumed as being fairly small and the speed of adjustment of the dynamic multiplier (which is infinite if IS-equilibrium is assumed) may be assumed to be large, we

\footnotetext{
${ }^{18}$ This would correspond to a strong Keynes effect in the corresponding working model of Chiarella and Flaschel (2000, ch. 6).
} 
have only one critical parameter left in the above proposition which may be crucial for the stability of the considered subsystem of the dynamics, the investment parameter $i_{u}$, potentially representing and accelerator of Harrodian type. This suggests that fiscal policy should be used to counteract the working of this accelerator mechanism which leads from higher capacity utilization to higher investment to higher goods demand and thus again to higher capacity utilization.

The following proposition formulates how fiscal policy should be designed in order to create damped oscillations around the balanced growth path of the model (if they are yet present).

Theorem 1 Assume an independent fiscal authority solely responsible for the control of business fluctuations (acting independently from the business cycle neutral fiscal policy of the government) which implements the following two rules for its activity oriented expenditures and their funding:

$$
g^{u}=-g_{u}(u-\bar{u}), \quad t^{u}=g_{u}(u-\bar{u})
$$

The budget of this authority is always balanced and we assume that the tributes $t^{u}$ are paid by asset holding households. The stability condition on $i_{u}$ is now extended to the consideration of the parameter $i_{u}-g_{u}$. Then: An anti-cyclical policy $g^{u}$ that is chosen in a sufficiently active way will enforce damped oscillations in the considered subdynamics if the savings rate $s_{c}$ of asset holders is sufficiently close to one (and if stock markets are sufficiently tranquil).

Therefore: An anti-cyclical policy that is chosen in a sufficiently active way will enforce damped oscillations in the considered subdynamics 1) if the savings rate of asset holders is sufficiently close to one and 2) if stock markets are sufficiently tranquil. Note that neither the steady state nor the laws of motions are changed through this introduction of such a self -determined business cycle authority, if $s_{c}=1$ holds true, which we assume to hold true in the following for reasons of simplicity.

Next we consider the same system but allow $\beta_{p}$ to become positive, though only small in amount. This means that $\omega$ which had previously entered the $m, b, y^{e}$ subsystem only through its steady state value now becomes a dynamic variable, 
giving rise to the 4D dynamical system

$$
\begin{aligned}
\dot{m} & =m\left(\mu-\left[\kappa \beta_{p}\left(\frac{y}{y^{p}}-\bar{u}\right)+\pi_{o}^{c}+i(\cdot)\right]\right), \\
\dot{b} & =g-t_{c}-\tau_{w} \omega \frac{y}{x}-\mu m-b\left[\kappa \beta_{p}\left(\frac{y}{y^{p}}-\bar{u}\right)+\pi_{o}^{c}+i(\cdot)\right], \\
\dot{y}^{e} & =\beta_{y^{e}}\left[c+i(\cdot)+\delta+g-y^{e}\right]+y^{e}(n-i(\cdot)), \\
\dot{\omega} & =\omega \kappa\left(\kappa_{w}-1\right) \beta_{p}\left(\frac{y}{y^{p}}-\bar{u}\right) .
\end{aligned}
$$

Proposition 2 The interior steady state of the dynamical system (68) is locally asymptotically stable if the conditions in proposition 1 are met and $\beta_{p}$ is sufficiently small.

Note here that the implication of this new condition for the considered subdynamics is also obtained by the assumption $\kappa_{w}=1$, i.e., workers and their representatives should always demand for a full indexation of their nominal wages to the rate of price inflation. This implies:

Theorem 2 Assume that the cost-push term in the money wage adjustment rule is given by the current rate of price inflation (which is perfectly foreseen). Then: the considered 4D subdynamics implies damped oscillations around the given steady state position of the economy.

This type of a scala mobile thus implies stability instead of - as might be expected - instability, since it simplifies the real wage channel of the model considerably. It needs however the following theorem in addition in order to really tame the wage-price spiral of the model.

Enlarging the system (68) by letting $\beta_{w}$ become positive we get the subsystem

$$
\begin{aligned}
\dot{m}= & m\left(\mu-\left(\kappa\left[\beta_{p}\left(\frac{y}{y^{p}}-\bar{u}\right)+\kappa_{p} \beta_{w}\left(\frac{y}{x l}-\bar{e}\right)\right]+\pi_{o}^{c}+i(\cdot)\right)\right), \\
\dot{b}= & g-t_{c}-\tau_{w} \omega \frac{y}{x}-\mu m \\
& -b\left(\kappa\left[\beta_{p}\left(\frac{y}{y^{p}}-\bar{u}\right)+\kappa_{p} \beta_{w}\left(\frac{y}{x l}-\bar{e}\right)\right]+\pi_{o}^{c}+i(\cdot)\right)
\end{aligned}
$$




$$
\begin{aligned}
\dot{y}^{e} & =\beta_{y^{e}}\left[c+i(\cdot)+\delta+g-y^{e}\right]+y^{e}(n-i(\cdot)), \\
\dot{\omega} & =\omega \kappa\left[\left(1-\kappa_{p}\right) \beta_{w}\left(\frac{y}{x l}-\bar{e}\right)+\left(\kappa_{w}-1\right) \beta_{p}\left(\frac{y}{y^{p}}-\bar{u}\right)\right], \\
\dot{l} & =l\left[-i_{q}(q-1)-i_{u}\left(\frac{y}{y^{p}}-\bar{u}\right)\right] .
\end{aligned}
$$

Proposition 3 The steady state of the dynamical system (69) is locally asymptotically stable if the conditions in proposition 2 are met and $\beta_{w}$ is sufficiently small.

Theorem 3 We assume that the economy is a consensus based one, where labor and capital have reached an agreement with respect to the scala mobile principle in the dynamics of money wages. Assume furthermore that capitalists and workers also agree against this background on the precept that additional money wage increases should be small in the boom $(u-\bar{u})$ and vice versa in the recession. This makes the steady state of the considered 5D subdynamics asymptotically stable.

We now enlarge the system further by letting $\beta_{n}$ become positive to obtain

$$
\begin{aligned}
\dot{m} & =m\left(\mu-\left(\kappa\left[\beta_{p}\left(\frac{y}{y^{p}}-\bar{u}\right)+\kappa_{p} \beta_{w}\left(\frac{y}{x l}-\bar{e}\right)\right]+\pi_{o}^{c}+i(\cdot)\right)\right), \\
\dot{b} & =g-t_{c}-\tau_{w} \omega \frac{y}{x}-\mu m-b\left(\kappa\left[\beta_{p}\left(\frac{y}{y^{p}}-\bar{u}\right)+\kappa_{p} \beta_{w}\left(\frac{y}{x l}-\bar{e}\right)\right]+\pi_{o}^{c}+i(\cdot)\right), \\
\dot{y}^{e} & =\beta_{y^{e}}\left[c+i(\cdot)+\delta+g-y^{e}\right]+y^{e}(n-i(\cdot)), \\
\dot{\omega} & =\omega \kappa\left[\left(1-\kappa_{p}\right) \beta_{w}\left(\frac{y}{x l}-\bar{e}+\left(\kappa_{w}-1\right) \beta_{p}\left(\frac{y}{y^{p}}-\bar{u}\right)\right)\right], \\
\dot{l} & =l\left[-i_{q}(q-1)-i_{u}\left(\frac{y}{y^{p}}-\bar{u}\right)\right], \\
\dot{v} & =y-(c+i(\cdot)+\delta+g)-v i(\cdot) .
\end{aligned}
$$

Proposition 4 The steady state of the dynamical system (70) is locally asymptotically stable if the conditions in proposition 3 are met and $\beta_{n}$ is sufficiently small. 
conomics: The Open-Access, Open-Assessment E-Journal

Theorem 4 The Metzlerian feedback between expected sales and output is given by

$$
y=\left(1+\alpha_{n^{d}}\left(n+\beta_{n}\right)\right) y^{e}-\beta_{n} v .
$$

This static relationship implies that lean production $\alpha_{n^{d}}$ or cautious inventory adjustment $\beta_{n}$ (or both) can tame the Metzlerian output accelerator.

We here do not introduce any exogenous regulating process for these Metzlerian sales-inventory adjustments, but simply assume that this inventory accelerator process is of a secondary nature in the business fluctuations generate by the dynamics, in particular if the control of the Harrodian goods market accelerator is working properly.

We now let $\beta_{\pi^{c}}$ become positive so that we then are back at the differential equation system

$$
\begin{aligned}
\dot{m}= & m \mu-m\left(\kappa\left[\beta_{p}(u-\bar{u})+\kappa_{p} \beta_{w}(e-\bar{e})\right]+\pi^{c}+i(\cdot)\right), \\
\dot{b}= & g-t_{c}-\tau_{w} \omega l^{d}-\mu m \\
& -b\left(\kappa\left[\beta_{p}(u-\bar{u})+\kappa_{p} \beta_{w}(e-\bar{e})\right]+\pi^{c}+i(\cdot)\right), \\
\dot{y}^{e}= & \beta_{y^{e}}\left(y^{d}-y^{e}\right)+y^{e}(n-i(\cdot)) \\
\dot{\omega}= & \omega \kappa\left[\left(1-\kappa_{p}\right) \beta_{w}(e-\bar{e})+\left(\kappa_{w}-1\right) \beta_{p}(u-\bar{u})\right], \\
\hat{l}= & n-i(\cdot)=-i_{q}(q-1)-i_{u}(u-\bar{u}), \\
\dot{v}= & y-y^{d}-i(\cdot) v \\
\dot{\pi}^{c}= & \alpha \beta_{\pi^{c}} \kappa\left[\beta_{p}(u-\bar{u})+\kappa_{p} \beta_{w}(e-\bar{e})\right]+(1-\alpha) \beta_{\pi^{c}}\left(\mu-n-\pi^{c}\right) .
\end{aligned}
$$

Proposition 5 The steady state of the dynamic system (71) is locally asymptotically stable if the conditions in proposition 4 are met and $\beta_{\pi}^{c}$ is sufficiently small.

Theorem 5 Assume that the business cycle is controlled in the way we have described it so far and that this implies that the fundamentalist expectations of inflation become dominant in the adjustment rule for the inflationary climate:

$$
\dot{\pi}^{c}=\beta_{\pi^{c}}\left(\alpha \hat{p}+(1-\alpha)(\mu-n)-\pi^{c}\right) .
$$

Choosing $\alpha$ sufficiently small guarantees the applicability of the preceding proposition. 
The economy will thus exhibit damped fluctuations if the parameter $\alpha$ in the law of motion the inflationary climate expression $\pi^{c}$ is chosen sufficiently small, which is a reasonable possibility if the business cycle is damped and actual inflation, here only generated by the market for goods:

$$
\hat{p} \sim \beta_{p}(u-\bar{u}) /\left(1-\kappa_{p}\right)+\pi^{c}
$$

is moderate. A stronger orientation of the change in the inflation climate on a return to the steady state rate of inflation thus helps to stabilize the economy.

Note here that the consideration of expectation formation on financial markets are still ignored (assumed as static). It is however obvious that an enlargement of the dynamics by these expectations does not destroy the shown stability properties if only fundamentalists are active, since this enlarges the Jacobian by a negative entry in its diagonal solely. Continuity then implies that a portion of chartists that is relatively small as compared to Fundamentalists will also admit to preserve the damped fluctuations we have shown to exist in the above sequence of propositions.

Proposition 6 The steady state of the dynamic system (71) is locally asymptotically stable if the parameter $\alpha_{\pi_{e}}$ is sufficiently small.

In order to get this result enforced by policy action, independently of the size of the chartist population, we introduce the following type of a Tobin tax on the capitals gains of equities:

$$
\begin{aligned}
\dot{\pi}_{e f} & =\beta_{\pi_{e f}}\left(\eta-\pi_{e f}\right), \\
\dot{\pi}_{e c} & =\beta_{\pi_{e c}}\left(\left(1-\tau_{e}\right) \hat{p}_{e}-\pi_{e c}\right) .
\end{aligned}
$$

Theorem 6 The Tobin tax parameter $\tau_{e}$ implies that damped business fluctuations remain damped for all tax rates chosen sufficiently large (below 100\%).

The objective the implementation of such Tobin tax (for all traders, irrespective of their expectations formation schemes, which are of course not observable) is to restrict to a certain extent the accelerating equity price expectations mechanism. The consequence of the implementation of such a tax is that the expectations of equity price gains - the relevant variable for the investment decisions of the chartists 
- are by diminished by $\tau_{e}$, being thus not $\hat{p}_{e}$, but $\left(1-\tau_{e}\right) \hat{p}_{e}$. Fundamentalists, in contrast, have a longer-term orientation and thus will quite likely care less for shortterm variations in the equity prices and the gains resulting from them. As a result, the development of the equity prices may be more oriented towards fundamentals and less towards the expectations of pure equity price gains. ${ }^{19}$

Furthermore, it should be pointed out that the introduction of such a capital gain tax also implies the establishment of an public agency which accumulates or deccumulates the reserve funds $R$ resulting from the financial markets taxation according to the rule

$$
\dot{R}=\tau_{e} \dot{p}_{e} E
$$

In order to keep again the laws of motion of the economy unchanged (to allow the application of the above stability propositions) we assume here that this public agency is independent from the other public institutions. The steady state value $\rho^{o}$ of the reserve funds - expressed per value unit of capital $p K-$ of this new agency is

$$
\rho^{o}=(R / p K)^{o}=\tau_{e}(\mu-n) / \mu<1 .
$$

This easily follows from the law of motion

$$
\hat{\rho}=\hat{R}-\hat{p}-\hat{K}=\frac{\dot{R}}{R} \frac{R}{p K}-\hat{p}-\hat{K}
$$

since there holds $\hat{p}-\hat{K}=\mu$ and $\hat{E}=n, q=1, \hat{p}_{e}=\hat{p}$ in the steady state. It is assumed that the reserves of this institution are sufficiently large so that they will not become exhausted during the damped business fluctuations generated by the model.

The stability results of the propositions are intuitively very appealing in view of what we know about Keynesian feedback structures and from what has been discussed in the preceding sections, since it basically states that the wage-spiral

\footnotetext{
${ }^{19}$ Furthermore, it should be pointed out that it is in the logic of such a tax system which may be monitored through a corresponding tax declaration scheme - that it should be in principle applied in a symmetric way so that not only capital gains are taxed, but also capital losses subsidized (so that the implementation of such a tax is entirely to the disadvantage of the asset holders of the model). The final implementation of such a system in reality, and thus the compromise with the status quo, is however a matter of political debate.
} 
must be fairly damped, the Keynesian dynamic multiplier be stable and not too much distorted by the emergence of Metzlerian inventory cycles, that the Harrodian knife-edge growth accelerator is weak, that and inflationary and capital gains expectations are fundamentalist in orientation and money demand subject to small transaction costs and fairly unresponsive to rate of return changes on financial assets (that is money demand is not close to a liquidity trap). Such assumptions represent indeed fairly natural conditions from a Keynesian perspective.

On this basis we obtained in the above theorems the result that independently conducted countercyclical fiscal policy can limit the fluctuations on the goods market, that an appropriate consensus between capital and labor can tame the wage-price spiral and that a Tobin tax can tame the financial market accelerator. Metzlerian inventory dynamics and fluctuations in the inflationary climate that is surrounding the economy may then also be weak and thus not endanger asymptotic stability. But what about monetary policy?

\subsection{Monetary Policy}

So far we have presumed that in the baseline model traditional monetary policy (as money supply and interest rate policy) is ineffective in the control of the economy between the short and the medium run. As monetary policy is set up it only effects the cash management process of asset holders, but leaves $M_{2}=M+B$ invariant. $^{20}$ Note however that such a monetary policy can be dangerous in the case of the liquidity trap, since this model allows for the equity owners attempt to a large degree to sell their equities against the fully liquid assets $M$ and $B$. This would imply - as in the current financial crisis - that the public could end up sitting on the bad assets.

The alternative is to suggest that the central bank buys the bad assets and drives up asset prices again. This is a demanding policy option that must be investigated and discussed in more detail. Yet this policy seems to have been pursued in the current financial market meltdown and this variant of monetary policy has recently come to the forefront in the discussion. Details may be beyond the scope of the present paper but we might make, as to this policy, some important

\footnotetext{
${ }^{20}$ Note that we have not introduced here into our model long bonds and yield spreads between bonds of different maturity. To do so might be subject of future research.
} 
observations. The fiscal authorities, the US-Treasury, has extensively purchased equity, for example by taking over Fannie Mae and Freddie Mac, and taking over shares of automobile companies. The Fed has purchased, in order to clean up banks' balance sheets, a large amount of complex securities (MBS and CDOs) to avoid a fire sales of bad assets and a downward spiral. It also undertook extensive lending to the private sector by accepting bad assets as collateral. This extensive purchase, or acceptance, of equity assets was a new policy variant coming to the forefront as the financial meltdown evolved in the years 2008/09. This attempt to rescue the financial and banking sectors, through the purchase of securities, was widely viewed as a step to prevent a system wide breakdown. ${ }^{21}$ Next we want to build into our macro model some elements of this new policy.

So far, in our baseline portfolio approach to Keynesian macrodynamics we have first formulated a truly tranquil monetary policy as far as the long-run is concerned, i.e., we assumed a constant growth rate of the money supply $\mu>n$. This policy was oriented towards the long run and implied in our model a positive inflation rate in the steady state. This rate should be chosen high enough to allow to avoid deflationary situations where the above described compromise between capital and labor may break down - since labor may be very opposed to money wage reductions (as Keynes (1936) already noted as a behavioral rule, a fact ignored by those economists who disregard the psychology of workers).

As previously stated, in the type of portfolio model we have presented here, a monetary policy only oriented towards the short-term rate of interest is ineffective unless it impacts the long-term interest rates and capital gain expectations on the stock market. Since long-term bonds are not included in the present model ${ }^{22}$ nor the debt issuing by firms (which only use equities as means of financing their investment), ${ }^{23}$ we interpret the following proposal of Keynes must in terms of the stock market in order to discuss his implications:

If the monetary authority were prepared to deal both ways on specified terms in debts of all maturities, and even more so if it were prepared

\footnotetext{
${ }^{21}$ This policy was actually anticipated by Bernanke et al. (2004).

${ }^{22}$ See Charpe et al. (2009) for a first attempt in this direction.

${ }^{23}$ To include debt issuance of firms would amplify the bubbles and bursts, since the interaction of asset price movements and leveraging is rather destabilizing, see Semmler and Bernard (2009).
} 
to deal in debts of varying degrees of risk, the relationship between the complex of rates of interest and the quantity of money would be direct. (Keynes (1936), p.205)

We do this in addition to the above monetary policy that concerns the longrun by assuming in extension of the 'Friedmanian' rule $\dot{M}=\mu M, \mu=$ const. as integration of the long- as well as short- and medium-run orientation of monetary policy a 'Keynesian' rule as follows: ${ }^{24}$

$$
\begin{aligned}
\hat{M} & =\mu-\beta_{m q}\left(q-q^{o}\right), \quad \text { with } \\
\mu M & =\dot{B}_{c}, \quad \dot{M}-\mu M=-\beta_{m q}\left(q-q^{o}\right) M=p_{e} \dot{E}_{c}
\end{aligned}
$$

This additional policy of the Central Bank takes the state of the stock market as measured by the gap between Tobin's $q$ and its steady state value $q^{o}=1$ as reference point in order to increase money supply above its long-run rate in the bust, by purchasing equities and by selling stock and decreasing therewith money supply below its long-run trend value in the boom. This is clearly a monetary policy that attempts to control the fluctuations in equity prices since it buys stocks when the stock market is weak and sells stocks in the opposite case. We stress that this policy is meant to be applied under normal conditions on financial markets and may not be so easily available in the cases where a liquidity trap is in operation.

In the treatment of the implications of the government (see also Sargent (1987, p.16)) we denoted by B the bonds held in the household sector and represented the ones currently purchased by the central bank $\left(\dot{B}_{c}\right)$ by putting the corresponding supply of new money into the (aggregated) government budget constraint (assuming as usual that interest payments to the central bank are channeled back into the actual government sector). Moreover taxes net of interest were assumed as being a parameter (per unit of capital) in order to suppress the interest income effects in the consumption function of asset holders. We now go one step further by continuing to use $E$ for equities that are privately held and by assuming for the ones held by the central bank $\left(E_{c}\right)$ that they have a reduced status only (exhibit no dividend payments and no voting rights). Dividend payments to the household

24 This makes Central Bank money now endogenous in a pronounced way. Note however that we do
not yet consider commercial banks and the endogeneity of the money supply that they are creating. 
sector thus remain as before. On this basis we assume that only $q=p_{e} E / p K$ enters the investment function of firms. This is clearly a restrictive assumption but it allows in the following theorem 7 (indicating a route for future research) that only the law of motion for real balances per unit of capital is changed by the above addition of a Keynes-type open market policy rule.

Transferred to the intensive form level this rule, which we call a Tobin rule in the following, then gives rise to the following law of motion for real balances per unit of capital:

$$
\begin{aligned}
\hat{m}= & \mu-\beta_{m q}\left(q-q^{o}\right)-(\hat{p}+\hat{K}) \\
= & \mu m-\beta_{m q}\left(q\left(m+b, r_{k}^{e}+\pi_{e}\right)-1\right) \\
& -\left(\kappa\left[\beta_{p}(u-\bar{u})+\kappa_{p} \beta_{w}(e-\bar{e})\right]+\pi^{c}+i(\cdot)\right) m
\end{aligned}
$$

as the only change in the model of this paper. In addition to holding government bonds it is assumed that the CB holds equities in a sufficient amount in order to pursue its short-run oriented stock market policy. This policy is sustainable in the long-run, since the CB buys stock when cheap and sells it when expensive.

We consider a proof for the statement that such a policy adds to the stability of the steady state of the dynamics by reconsidering only the first stage by our previous cascade of stable matrices approach (see e.g. Chiarella et al. (2006)).

Theorem 7 The initially considered, now augmented 3D subdynamics of the full 9D dynamics:

$$
\begin{aligned}
\dot{m} & =m\left(\mu-\beta_{m q}\left(q-q^{o}\right)-\left(\pi_{o}^{c}+i(\cdot)\right)\right), \\
\dot{b} & =g-t_{c}-\tau_{w} \omega \frac{y}{x}-\mu m-b\left(\pi_{o}^{c}+i(\cdot)\right), \\
\dot{y}^{e} & =\beta_{y^{e}}\left[c+i(\cdot)+\delta+g-y^{e}\right]+y^{e}(n-i(\cdot)) .
\end{aligned}
$$

can be additionally stabilized (by increasing the parameter range where damped oscillations are established and by making the originally given damped oscillations even less volatile) by an increasing parameter value $\beta_{m q}$ of the new term $-\beta_{m q}(q-$ $\left.q^{o}\right) m$ in the law of motion for real balances, if anticyclical fiscal policy is sufficiently active to make the dynamic multiplier process a stable one (by neutralizing the Harrodian investment accelerator) and if the savings rate $s_{c}$ of asset holders 
is sufficiently close to one (which allows to ignore effects from taxation on the consumption of asset holders).

Sketch of Proof: Under the conditions assumed to hold on the asset markets we can again solve for Tobin's $q$ explicitly and get:

$$
q=\frac{f_{e}\left(r_{e}^{e}\right)}{1-f_{e}\left(r_{e}^{e}\right)}(m+b)=q\left(r_{e}^{e}, m+b\right), \quad \text { i.e., } \quad \frac{\partial q}{\partial r_{e}^{e}}=\frac{f_{e}^{\prime}\left(r_{e}^{e}\right)}{\left(1-f_{e}\left(r_{e}^{e}\right)\right)^{2}}(m+b)>0
$$

The Routh-Hurwitz polynomial of the Jacobian matrix is thereby augmented by the principal minors to be obtained from the additional matrix:

$$
\begin{aligned}
\dot{m} & =-\beta_{m q}\left(q-q^{o}\right) m \\
\dot{b} & =g-t_{c}-\tau_{w} \omega \frac{y}{x}-\mu m-b\left(\pi^{c}+i(\cdot)\right) \\
\dot{y}^{e} & =\beta_{y^{e}}\left[c+i(\cdot)+\delta+g-y^{e}\right]+y^{e}(n-i(\cdot))
\end{aligned}
$$

which only differs from the original one in its first row. This row can be used to eliminate the $i_{q}(\cdot)$ term in the $i(\cdot)$ function when calculating the principal minors of this additional Jacobian matrix. From this simplification one then easily gets that the Routh-Hurwitz coefficients $a_{1}, a_{2}$ and $a_{3}$ of the characteristic polynomial of the augmented Jacobian exceed the originally given ones (note that according to lemma 2 we have $q_{m}>q_{b}$ ), while the determinant of the Jacobian in the final Routh-Hurwitz condition $a_{1} a_{2}-a_{3}$ is dominated by the additions to $a_{1}, a_{2}$.

The important means to stabilize the economy or to make it at least less volatile are therefore given here by Keynesian anticyclical demand management, consensus based wage management, and Tobin type management of the financial market accelerating processes and - in the full dynamically system hopefully - also by the above willingness of the $\mathrm{CB}$ to trade not only in bonds, but also in equities (or in long-term bonds as in Köper (2003)). Due to space limitations this latter statement must however be left here for future research, in particular if an impact of the equities that are held by the central bank on the real side of the economy is taken into consideration. 


\section{Conclusions}

Summing up, according to the theoretical approach pursued in this paper, it is not so much the individual behavior of economic agents (firms, households, institutions), but rather the interconnectedness of agents and markets which can produce the stabilizing or destabilizing feedback effects within the dynamical system we have investigated in this paper. The behavior of the agents was by and large a fairly simple one, while the dynamics they generated was subject to Harrodian and Metzlerian quantity accelerators, concerning the capacity utilization rate of firms and their inventory holdings, as well as the positive interaction between the state of confidence, measured by Tobin's $q$, and private investment and thus economic activity. Moreover, such centrifugal forces were also present in the financial part of the model, there concerning the interaction of capital gains and capital gain expectations, operating in an otherwise stable portfolio model which was characterized by gross-substitutability. Finally, the real-financial market interaction between these two accelerating mechanisms was also strongly impacted by a wage-price spiral, also characterized by centrifugal dynamical forces under certain assumptions on its adjustment parameters.

In the context of our proposed model we then argued for the necessity of adequate labor, fiscal and monetary policies which may induce stability in an otherwise, when left to itself, unstable macroeconomic environment. More specifically, we have shown that countercyclical labor market and fiscal policies, in terms of a wage management characterized by the cooperation between capital and labor in a corporative system resulting in a tranquilized wage-price spiral and a countercyclical demand management by a fiscal authority, may be powerful means to make the business cycle not only less volatile, but in fact damped and maybe also monotonically converging to the balanced growth path of the economy.

Within the theoretical closed-economy framework discussed in this paper, however, these fiscal and labor market policies are necessary, but not sufficient conditions for a comprehensive macroeconomic stabilization economic policy setup. Indeed, as we have discussed here, if the financial markets are primarily driven by the expectation of future capital gains in the equity markets and only to a much lesser extent by short-term interest rate changes, a necessary condition for the dampening of business cycles at the macro level is a monetary policy focused 
on the stabilization of financial markets. On the basis of the results of the reduced 3D system analyzed in the previous section, this should be undertaken by the introduction of a Tobin tax on capital gains, together with the implementation of a Tobin rule - by means of buying and selling equities of the non-financial sector (and other risk-bearing securities) - in place of a Taylor rule which, as assumed here, may turn out to be uncapable to stabilize the real and financial markets.

Acknowledgement: We would like to thank the referees of this journal for valuable comments and suggestions on the working paper version of this article.

\section{Appendix}

\section{Derivation of the Model in Intensive Form}

In its intensive form, all stock and flow variables are expressed in per unit of capital terms in the laws of motion and also in the associated algebraic equations (that need to be inserted into the laws of motion in order to obtain an autonomous dynamical system). We thus divide nominal stock and flow variables by the nominal value of the capital stock $p K$ and all real ones by $K$, the real capital stock. This allows the determination of a (unique) economic steady state solution as an interior point of rest of the resulting nine state variables.

We begin with the intensive form of some necessary definitions or identities, which we need to represent the dynamical system in a sufficiently comprehensible form. Thus we set

$$
\begin{aligned}
Y / K & =y=\left(1+\alpha_{n^{d}}\left(n+\beta_{n}\right)\right) y^{e}-\beta_{n} v, \\
Y^{e} / K & =y^{e} \\
N / K & =v, \\
L^{d} / K & =l^{d}=y / x \\
L / K & =l \\
e & =l^{d} / l \\
u & =y / y^{p} \\
r_{k}^{e} & =y^{e}-\delta-\omega l^{d}, \\
C / K & =c=\left(1-\tau_{w}\right) \omega l^{d}+\left(1-s_{c}\right)\left(y^{e}-\delta-\omega l^{d}-t_{c}\right),
\end{aligned}
$$




$$
\begin{aligned}
I / K & =i(\cdot)=i_{q}(q-1)+i_{u}(u-\bar{u})+n, \\
Y^{d} / K & =y^{d}=c+i(\cdot)+\delta+g, \\
p_{e} E /(p K) & =q=q\left(m, b, r_{k}^{e}, \pi_{e}\right), \\
r_{e}^{e} & =r_{k}^{e} / q+\pi_{e} \\
\pi_{e} & =\alpha_{\pi_{e}} \pi_{e c}+\left(1-\alpha_{\pi_{e}}\right) \pi_{e f} .
\end{aligned}
$$

The above equations describe output and employment per unit of capital, the rate of utilization of the existing stock of labor and capital, the expected rate of return on capital, consumption, investment and aggregate demand per unit of capital, Tobin's average $q$, and the expected rate of return on equities (including expected capital gains $\pi_{e}$ ).

Now we translate the laws of motion of the dynamically endogenous variables into capital intensive form. The law of motions for the nominal wages and price level stated in eqs. (38) and (39) interact instantaneously and thus depend on each other. Solving these two linear equations for $\hat{w}$ and $\hat{p}$ gives ${ }^{25}$

$$
\begin{aligned}
\hat{w} & =\kappa\left(\beta_{w}(e-\bar{e})+\kappa_{w} \beta_{p}(u-\bar{u})\right)+\pi^{c}, \\
\hat{p} & =\kappa\left(\beta_{p}(u-\bar{u})+\kappa_{p} \beta_{w}(e-\bar{e})\right)+\pi^{c},
\end{aligned}
$$

with $\kappa=\left(1-\kappa_{w} \kappa_{p}\right)^{-1}$. From these two inflation rates one can compute the growth law of real wages $\omega=w / p$ by means of the definitional relationship $\hat{\omega}=\hat{w}-\hat{p}$, from which eq. (46) arises.

Next we obtain the set of equations that explains the dynamical laws of the expected rate of inflation, the labor capital ratio, the expected sales, and the stock of inventories in intensive form given by eqs.(47) - (50), respectively.

Eq. (47) is almost the same as in the extensive form model, but here the term $\hat{p}-\pi^{c}$ is substituted by use of eq. (79). Eq. (48), the law of motion of relative factor endowment, follows from eqs. (4) and (23) and is given by the (negative) of the investment function as far as its dependence on asset markets and the state of the business cycle are concerned. Eq. (49) is obtained by taking the time derivative of $y^{e}$, so that

$$
\dot{y}^{e}=\frac{d\left(Y^{e} / K\right)}{d t}=\frac{\dot{Y}^{e} K-Y^{e} \dot{K}}{K^{2}}=\frac{\dot{Y}^{e}}{K}-y^{e} i(\cdot)=\beta_{y^{e}}\left(y^{d}-y^{e}\right)+y^{e}(n-i(\cdot)) .
$$

${ }^{25}$ For details of the calculations involved see Chiarella and Flaschel (2000) and Köper (2003). 
In essentially the same way one obtains eq. (50).

The law of motion of the aggregate expectation of equity price inflation given by eq. (51) results from taking the time derivative of $\pi_{e}$

$$
\dot{\pi}_{e}=\alpha_{\pi_{e c}} \dot{\pi}_{e c}+\left(1-\alpha_{\pi_{e c}}\right) \dot{\pi}_{e f}
$$

and inserting therein the laws of motion governing the expectations about the equity prices given by eqs. (14) and (15).

Finally, the laws of motion for real balances and real bonds per unit of capital have to be derived. Based on the knowledge of the laws for inflation $\hat{p}$ and investment $i(\cdot)$ we can derive the differential equation for bonds per unit of capital shown in eq. (52) from

$$
\dot{b}=\frac{d(B / p K)}{d t}=\frac{\dot{B}}{p K}-b(\hat{p}+i(\cdot))
$$

where $\dot{B}$ is given by eq. (37). The same idea is used for the changes in the money supply.

\section{References}

Abreu, D., and Brunnermeier, M. (2003). Bubbles and Crashes. Econometrica, 71: 173-204.

Bernanke, B., Reinhard, V. R., and Sack, B. (2004). Monetary Policy Alternatives at the Zero Bound: An Empirical Assessment. Discussion paper 48, Federal Reserve Board, Washington. D.C.

Brunnermeier, M. (2009). Bubbles. Forthcoming as entry in Palgrave, http: //www.princeton.edu/ markus/research/papers/bubbles_survey.pdf.

Charpe, M., Flaschel, P., Hartmann, F., and Proaño, C. (2009). Stabilizing an Unstable Economy: Fiscal and Monetary Policy, Stocks, and the Term Structure of Interest Rates. Working paper, Center for Empirical Micro- and Macroeconomics, Bielefeld University. 
Chiarella, C., and Flaschel, P. (2000). The Dynamics of Keynesian Monetary Growth. Macro Foundations. Cambridge, UK: Cambridge University Press.

Chiarella, C., Flaschel, P., and Franke, R. (2005). Foundations for a Disequilibrium Theory of the Business Cycle. Qualitative Analysis and Quantitative Assesment. Cambridge, U.K.: Cambridge University Press.

Chiarella, C., Flaschel, P., Franke, R., and Semmler, W. (2006). A High-Dimensioal Model of Real-Financial Market Interaction: The Cascades of Stable Matrices Approach. In C. Chiarella, P. Flaschel, R. Franke, and W. Semmler (Eds.), Quantitative and Empirical Analysis of Nonlinear Dynamic Macromodels, pages 359 - 383. Amsterdam: Elsevier.

Chiarella, C., Flaschel, P., Groh, G., and Semmler, W. (2000). Disequilibrium, Growth and Labor Market Dynamics. Macro Perspectives. Heidelberg: Springer.

De Grauwe, P., and Grimaldi, M. (2006). The Exchange Rate in a Behavioral Finance Framework. Princeton University Press.

Farmer, R. E. A. (2010). How to Reduce Unemployment: A New Policy Proposal. Journal of Monetary Economics. Carnegie Rochester Conference Series on Public Policy, forthcoming.

Franke, R. (1996). A Metzlerian Model of Inventory Growth Cycles. Structural Change and Economic Dynamics, 2: 243-262.

Franke, R., and Semmler, W. (1999). Bond Rate, Loan Rate and Tobin's q in a Temporary Equilibrium Model of the Financial Sector. Metroeconomica, 50(3): $351-385$.

Keynes, J. M. (1936). The General Theory of Employment, Interest, and Money. London: MacMillan.

Köper, C. (2003). Real-Financial Interaction in Contemporary Models of AS-AD Growth. Bern: Peter Lang.

Mas-Colell, A., Whinston, M. D., and Green, J. R. (1995). Microeconomic Theory. New York: Oxford University Press. 
Metzler, L. A. (1941). The Nature and Stability of Inventory Cycles. Review of Economic Statistics, 23: 113-129.

Minsky, H. P. (1982). Stabilizing an Unstable Economy. New York: McGraw Hill, 2 edition.

Rose, H. (1967). On the Non-Linear Theory of the Employment Cycle. Review of Economic Studies, 34: 153-173.

Rose, H. (1990). Macroeconomic Dynamics: A Marshallian Synthesis. Cambridge: Blackwell.

Sargent, T. J. (1987). Macroeconomic Theory. New York: Academic Press, 2nd edition.

Semmler, W., and Bernard, L. (2009). Boom-Bust Cycles: Leveraging, Complex Securities and Asset Prices. Discussion paper, New York: The New School University.

Tobin, J. (1969). A General Equilibrium Approach to Monetary Theory. Journal of Money, Credit, and Banking, 1: 15-29.

Tobin, J. (1980). Asset Accumulation and Economic Activity. Oxford; Basil Blackwell. 


\section{Conomics}

The Open-Access, Open-Assessment E-Journal

Please note:

You are most sincerely encouraged to participate in the open assessment of this article. You can do so by either recommending the article or by posting your comments.

Please go to:

www.economics-ejournal.org/economics/journalarticles/2010-21

The Editor 
You are logged into UlrichsWeb LOG OUT

GLOBAL SERIALS DIRECTORY Quick ISSN

Advanced SearchBrowseListsHelpMy Account Ulrich's AlertUlrich's Update

\section{Economics}

$\triangle$ BACK TO RESULTS

SEARCH MY LI BRARY'S CATALOG: ISSN Search | Title Search

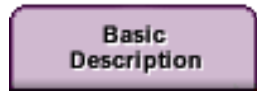

Abstracting/
Indexing 8 Article
Access

Publisher \&
Ordering
Information

Advertising, Rights,

Demographics

\section{GS.F.X}

Click highlighted text for a new search on that item.

\section{ISSN:}

1864-6042

Title:

Economics

Publishing Body: Universitaet Kiel, Institut fuer Weltwirtschaft

Country:

Status:

Germany

Frequency:

Document Type: Journal; Academic/Scholarly

Refereed: Yes

Abstracted/I ndexed: Yes

Media:

Language:

Price:

Subject:

Dewey \#:

LC\#:

Editor(s):

URL:

Description:
Online - full text

Text in English

Free

(effective 2010)

BUSINESS AND ECONOMICS

330

HB1

Dennis J Snower

http://www.economics-ejournal.org

Aims to integrate the analysis and lessons from various

fields of economics with the aim of providing new insights, that are not accessible from any particular sub-discipline of economics.
Back to Top

Add this item to:

(select a list)

\section{Request this title:}

I'd like to request this title.

Corrections:

Submit corrections to Ulrich's about this title.

Publisher of this title?

If yes, click GO! to contact Ulrich's about updating your title listings in the Ulrich's database.
GO

- $\underline{\text { Print }} \cdot \underline{\text { Download }} \cdot \underline{\text { E-mail }}$

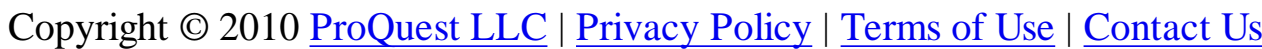

